\title{
Three-Level Supply Chain Coordination under Disruptions Based on Revenue-Sharing Contract with Price Dependent Demand
}

\author{
Qinghua Pang, Yuer Chen, and Yulu Hu \\ School of Business Administration, Hohai University, Changzhou 213022, China \\ Correspondence should be addressed to Qinghua Pang; pangqh77@126.com
}

Received 29 July 2014; Revised 28 November 2014; Accepted 30 November 2014; Published 21 December 2014

Academic Editor: Douglas R. Anderson

Copyright (C) 2014 Qinghua Pang et al. This is an open access article distributed under the Creative Commons Attribution License, which permits unrestricted use, distribution, and reproduction in any medium, provided the original work is properly cited.

Considering the market demand is stochastic and dependent on price, this paper shows that the revenue-sharing contract could coordinate a three-level supply chain consisting of one manufacturer, one distributor, and one retailer under normal environment. However, the original revenue-sharing contract cannot coordinate the supply chain under disruptions in circumstances of certain incidents leading to significant changes in market demand and causing additional deviation costs. To solve the problem, this essay introduces two improved forms of revenue-sharing contract: a mixed contract form based on a quantity discount policy and a pure form, which are characterized by antidisruption ability. The model of improved revenue-sharing contract is optimized when the market demand is in the additive form or in the multiplicative form with price dependent demand. Formulas are given to calculate the optimal contract parameters. Finally, this essay demonstrates the accuracy of the model of improved revenue-sharing contract with the help of numerical examples.

\section{Introduction}

In recent years, some serious incidents attract attention from all over the world, such as "SARS" in China in 2003, the southern China snow disaster in 2008, the earthquake in Japan in 2011, and the bird flu of H7N9 in 2013. These emergencies significantly influenced supply chain systems, resulting in impracticable plans in terms of production and storage as well as uncoordinated supply chains. It has been proved that developing reasonable coping strategies for emergencies is an effective way to improve the operation ability and realize the great potential of the supply chain. Therefore, it is of great significance to study the ability of the supply chain to cope with the emergencies and develop disruption management.

Abundant research has been conducted on how to deal with serious contingencies based on the two-level supply chain coordination. For example, Huang et al. [1] studied disruption management for supply chain coordination with exponential demand function and stated that the price discount contract can be used to coordinate the supply chain under demand disruptions. Xiao et al. [2] analyzed coordination of supply chain after demand disruptions when retailers compete; Xiao and Qi [3] discussed price competition, cost and demand disruptions, and coordination of a supply chain with one manufacturer and two competing retailers. On the basis of Xiao and Qi [3], Chen and Xiao [4] considered demand disruption and coordination of the supply chain with a dominant retailer. Yu et al. $[5,6]$ improved the linear quantity discount contract and the wholesale price contract to coordinate the supply chain. In addition, they pointed out that the supplier would change the production plan and start the disruption management only when the change of market demand is great enough. Teng et al. [7] explored the quantity discount contract based on the equilibrium model to coordinate the supply chain. Ma and Zhou [8] looked into the option contract to coordinate supply chain with demand disruptions. Zhang and Chen [9] took VMI into consideration when dealing with demand disruption. Sun and $\mathrm{Ma}$ [10] and Cao and Lai [11] investigated how to use revenue-sharing contract to coordinate supply chain under disruptions. Jiang 
and Cui [12] researched the conditions of the centralized supply chain and the decentralized supply chain under demand disruptions by setting the parameters of a target rebate contract. Qin and Cao $[13,14]$ studied how to use option contract and rebate and penalty contract to coordinate supply chains under demand disruption. Zhang et al. [15] introduced how to coordinate a one-manufacturer-two-retailer supply chain with demand disruptions by revenue-sharing contracts. Hou et al. [16] analyzed a buy-back contract between a buyer and a backup supplier when the buyer's main supplier experiences disruptions. Qi et al. [17] described a onesupplier-one-retailer supply chain that experienced a disruption in demand during the planning horizon and explained derived conditions under which the supply chain could be coordinated by using wholesale quantity discount policies.

There is little literature to study the three-level supply chain under demand disruption. Based on Yu et al. [5], Wang and $\mathrm{Hu}[18]$ investigated an optimal strategy for three-level centralized and decentralized supply chain responding to the disruptions while considering the market scale is changeable and deviation cost is nonlinear. Hu and Wang [19] looked into the impacts on the three-level supply chain under disruptions and improved a price discount contract which promotes antidisruption. Pang [20] came up with an improved revenuesharing contract which is characterized by an antidisruption ability when faced with demand disruptions. Sun and Zou [21] demonstrated the buy-back contract to coordinate the three-level supply chain under disruptions.

Coordination and operation of three-level supply chain are more complicated compared with those of two-level supply chain. Three-level supply chain is not the simple superposition of two two-level supply chains. In fact, the supply chain is usually characteristic of three-level structure and above in reality. It is equipped with multitransactions, which will be affected more profoundly by disruptions. Therefore, it is significant to study coordination of the threelevel supply chain under disruptions.

However, in the three-level supply chain research literatures mentioned above, all of them do not take the sale price into account under disruptions. The sale price is undoubtedly one of the most important factors which exert significant effect on the market demand [22-25]. Yu and Chen [26] studied the effect of the disruptions on the coordinated twolevel supply chain and pointed out the optimal emergency price decision distortion phenomena from the perspective of retailer to supply chain. As a result, we need to study the impacts of the disruption on the three-level supply chain with price dependent demand. In addition, the contracts mentioned in the literatures, such as the one proposed by $\mathrm{Hu}$ and Wang [19], are models which are based on quantity discount policy. Actually, the contract based on quantity discount policy is a mixed contract, which probably cannot be applied to the business administration due to its various drawbacks including high complexity and regulatory cost.

This paper studies how to use revenue-sharing contract $[27,28]$ to coordinate a three-level supply chain under disruptions with price dependent demand. Compared with the existing literature on disruption management for supply chain coordination, this paper throws new light in the following three aspects. First of all, it studies the coordination of three-level supply chain under disruptions with price dependent demand. Furthermore, it not only puts forward the revenue-sharing contract based on quantity discount policy put forward, but also proposes the pure form of the revenue-sharing contract, which has not been discussed before. Both forms of the revenue-sharing contract have antidisruption ability. Finally, based on the hypothesis that the demand and the retail price satisfy additive form (or multiplicative form), we optimize the revenue-sharing contract model and give out the method to calculate the optimal parameters (inventory quantity and retail price).

The rest of the paper is organized as follows. Section 2 introduces model assumptions and notations. Section 3 studies the coordination of the three-level supply chain based on the revenue-sharing contract under normal environment with price dependent demand. Section 4 analyses the impact of disruptions on the three-level supply chain coordination and proposes two different revenue-sharing contract models. Section 5 demonstrates the optimization of the improved revenue-sharing contract on the basis of the hypothesis that the demand and the retail price satisfy additive form or multiplicative form. Section 6 displays the numerical examples. Section 7 summarizes this paper.

\section{Model Descriptions}

The supply chain introduced in this paper is made up of one manufacturer $(m)$, one distributor $(d)$, and one retailer $(r)$. An upstream member provides a single product to a downstream member, and the retailer faces a stochastic demand that is dependent on the sale price. Before the sale season, both the distributor and the retailer have only one chance to buy products. All members are confronted with neutral risks and information is symmetric among them.

Assume $p$ is the sales price of unit product; $c_{i}$ represents supply chain member's marginal unit cost $(i=m, d, r)$ and $c=c_{r}+c_{d}+c_{m} ; v$ means salvage value for unsold unit product $(v<c)$; $Q$ stands for order quantity; $w_{i}^{j}$ is the wholesale price that upstream member charges downstream member in $j$ condition $(j=c, d ; i=m, d)$; here, $j=c$ means in the centralized supply chain condition and $j=d$ means in the decentralized supply chain condition; $x$ denotes the stochastic demand when the retail price is $p$, with probability density function $f(x \mid p)$ and continuously differentiable cumulated distribution function $F(x \mid p)$. Furthermore the demand is the decreasing function of retail price, which means $\partial F(x \mid p) / \partial p>0$; so when the retail price is $p$, the expected sale quantity is $S(Q, p)=E \min (Q, x)=Q-$ $\int_{0}^{\mathrm{Q}} F(x \mid p) d x$, where $\partial S(Q, p) / \partial p<0$; the expected unsold quantity is $I(Q, p)$, where $I(Q, p)=Q-S(Q, p)$. In particular, it is reasonable that $w_{d}^{d}>w_{m}^{d}+c_{d}, v<c<p$, and $w_{m}^{d}+c_{r}<p$.

Unexpected changes of the market demand are actually in practice under disruptions. For example, the outbreak of SARS caused a large sudden demand for respirators; the epidemic of bird flu influenced a large degree of the demand for live birds. Therefore, the sudden change of the market demand under disruptions will cause certain deviation costs 
that did not exist before. The deviation costs may be generated by the overtime production and the expedited delivery for an increased demand and the extra inventory holding and possible disposal for a decreased demand. We assume that $\alpha_{i}$ is the unit cost of the distributor $(i=d)$ and the manufacturer $(i=m)$ when the market demand is increasing under disruptions; then, $\alpha=\alpha_{d}+\alpha_{m}$. At the same time, $\beta_{i}$ is the unit cost of the retailer $(i=r)$, the distributor $(i=d)$, and the manufacturer $(i=m)$ when the market demand is decreasing under disruptions. As a result, $\beta=\beta_{i}+\beta_{d}+\beta_{m}$.

\section{Supply Chain Coordination under Normal Environment}

In this section, we study how to use revenue-sharing contract to coordinate the three-level supply chain under normal environment with price dependent demand. We assume that the retailer would keep a quota $\phi_{2}$ of his revenue and would give the rest $\left(1-\phi_{2}\right)$ to the distributor and this would be balanced by a lower price $w_{d}^{c}$. Similarly, the distributor would keep a quota $\phi_{1}$ of his revenue and give the rest $\left(1-\phi_{1}\right)$ to the manufacturer and this would be balanced by a lower price $w_{m}^{c}$. To analyze the problem conveniently, it is assumed that the distributor and the retailer both accept the revenue-sharing contract $\left(w_{m}^{c}, \phi_{1}\right)$ and $\left(w_{d}^{c}, \phi_{2}\right)$. Then, the profit functions of the supply chain system, the retailer, the distributor, and the manufacturer can be described, respectively, as

$$
\begin{aligned}
\prod_{t}(Q, p)= & p S(Q, p)+v I(Q, p)-c Q \\
& =(p-v) S(Q, p)-(c-v) Q \\
\prod_{r}^{c}(Q, p)= & \phi_{2}[p S(Q, p)+v I(Q, p)]-c_{r} Q-w_{d}^{c} Q \\
= & \phi_{2}(p-v) S(Q, p)-\left(c_{r}+w_{d}^{c}-\phi_{2} v\right) Q, \\
\prod_{d}^{c}(Q)= & \phi_{1}\left[\left(1-\phi_{2}\right)(p S(Q, p)+v I(Q, p))+w_{d}^{c} Q\right] \\
& -c_{d} Q-w_{m}^{c} Q \\
= & \phi_{1}\left(1-\phi_{2}\right)(p-v) S(Q, p) \\
& -\left[c_{d}+w_{m}^{c}-\phi_{1}\left(1-\phi_{2}\right) v-\phi_{1} w_{d}^{c}\right] Q
\end{aligned}
$$

$$
\begin{aligned}
& \prod_{m}^{c}(Q) \\
&=\left(1-\phi_{1}\right)\left[\left(1-\phi_{2}\right)(p S(Q, p)+v I(Q, p))+w_{d}^{c} Q\right] \\
&+w_{m}^{c} Q-c_{m} Q \\
&=\left(1-\phi_{1}\right)\left(1-\phi_{2}\right)(p-v) S(Q, p) \\
&-\left[c_{m}-w_{m}^{c}-\left(1-\phi_{1}\right)\left(1-\phi_{2}\right) v-\left(1-\phi_{1}\right) w_{d}^{c}\right] Q .
\end{aligned}
$$

Theorem 1. Revenue-sharing contract can coordinate the three-level supply chain under normal environment with price dependent demand when $w_{d}^{c}$ and $w_{m}^{c}$ satisfy

$$
\begin{aligned}
& w_{d}^{c}=\phi_{2} c-c_{r}, \\
& w_{m}^{c}=\phi_{1} c-\phi_{1} c_{r}-c_{d} .
\end{aligned}
$$

Proof. Comparing (1) with (2), we can get $\partial \prod_{r}^{c}(Q, p) / \partial p=$ $\phi_{2} \partial \prod_{t}(Q, p) / \partial p$, which means the optimal retail price of $(2)$ also satisfies (1). Namely, the optimal retail price of the retailer within revenue-sharing contract is equal to the optimal retail price of the centralized supply chain.

For supply chain members, they should consider how to make decisions to make the optimal profit. Then, the retailer needs to decide his order quantity $Q_{r}^{c}$ and retail price $p$ when he accepts revenue-sharing contract $\left(w_{d}^{c}, \phi_{2}\right)$. Similarly, the distributor and the manufacturer are supposed to decide his order (production) quantity $Q_{d}^{c}\left(Q_{m}^{c}\right)$.

An imperative condition is that the optimal order quantity of the retailer is equal to that of supply chain system if revenue-sharing contract can coordinate three-level supply chain, which is $\partial \prod_{r}^{c}\left(Q_{r}^{c *}, p\right) / \partial Q_{r}^{c}=\partial \prod_{t}\left(Q_{t}^{*}, p\right) / \partial Q_{t}=0$. In addition, according to our hypothesis, if a rational distributor (manufacturer) wants to maximize his profit within revenue-sharing contract, his optimal order (production) quantity should be equal to that of the retailer, which is $\partial \prod_{r}^{c}\left(Q_{r}^{c *}, p\right) / \partial Q_{r}^{c}=d \prod_{d}^{c}\left(Q_{d}^{c *}\right) / d Q_{d}^{c}=d \prod_{m}^{c}\left(Q_{m}^{c *}\right) / d Q_{d}^{c}=0$. To describe the problem conveniently, here we let $Q_{r}^{c}=Q_{d}^{c}=$ $Q_{m}^{c}=Q_{t}=Q$.

Then, based on (1) (5), we can get (5). Taking (5) into (2) (4), we can get

$$
\begin{aligned}
\prod_{r}^{c}(Q, p) & =\phi_{2} \prod_{t}(Q, p), \\
\prod_{d}^{c}(Q) & =\phi_{1}\left(1-\phi_{2}\right) \prod_{t}(Q, p), \\
\prod_{m}^{c}(Q) & =\left(1-\phi_{1}\right)\left(1-\phi_{2}\right) \prod_{t}(Q, p) .
\end{aligned}
$$

From (6), it is shown that the profit functions of the supply chain members are all affine functions of the whole supply chain's profit function. So in this condition, the revenue-sharing contract can coordinate the three-level supply chain.

Theorem 1 means the revenue-sharing contract can work under normal environment with price dependent demand when $w_{d}^{c}$ and $w_{m}^{c}$ satisfy (5). However, if the supply chain members are willing to use the revenue-sharing contract to coordinate supply chain in reality, their profits should not be less than the profit that they obtain in decentralized supply chain. Therefore, we should consider the participation constraint in supply chain practice. Namely, for the retailer, the distributor, and the manufacturer, their profit function should, respectively, satisfy the following: (1) $\prod_{r}^{c}(Q, p) \geq$ $\prod_{r}^{d}(\mathrm{Q}, \mathrm{p}) ;(2) \prod_{d}^{c}(\mathrm{Q}) \geq \prod_{d}^{d}(\mathrm{Q}) ;(3) \prod_{m}^{c}(\mathrm{Q}) \geq \prod_{r}^{d}(\mathrm{Q})$. 
Here, the superscript $d$ means decentralized decision-making mode. From the participation constraints, we can get that the revenue-sharing ratios $\phi_{1}$ and $\phi_{2}$ should satisfy

$$
\begin{aligned}
\phi_{2} & \left(p^{c}-v\right) S\left(Q^{c}, p^{c}\right)-\left(c_{r}+w_{d}^{c}-\phi_{2} v\right) Q^{c} \\
\geq & \left(p^{d}-v\right) S\left(Q^{d}\right)-\left(w_{d}^{d}+c_{r}-v\right) Q^{d}, \\
\phi_{1} & \left(1-\phi_{2}\right)\left(p^{c}-v\right) S\left(Q^{c}, p^{c}\right) \\
& -\left[c_{d}+w_{m}^{c}-\phi_{1}\left(1-\phi_{2}\right) v-\phi_{1} w_{d}^{c}\right] Q^{c} \\
\geq & \left(w_{d}^{d}-c_{d}-w_{m}^{d}\right) Q^{d}, \\
(1- & \left.\phi_{1}\right)\left(1-\phi_{2}\right)\left(p^{c}-v\right) S\left(Q^{c}, p^{c}\right) \\
& \quad-\left[c_{m}-w_{m}^{c}-\left(1-\phi_{1}\right)\left(1-\phi_{2}\right) v-\left(1-\phi_{1}\right) w_{d}^{c}\right] Q^{c} \\
\geq & \left(w_{m}^{d}-c_{m}\right) Q^{d} .
\end{aligned}
$$

In (7), $Q^{i}(i=c, d)$ is the order quantity and $p^{i}(i=c, d)$ is the retail price of the retailer, respectively, where $i=c$ means that it is in revenue-sharing contract condition and $i=d$ means it is in decentralized supply chain condition. Due to the complexity of (7), we do not take into account the participation constraints of $\phi_{1}$ and $\phi_{2}$ in the subsequent discussion.

In addition, $w_{d}^{c}$ and $w_{m}^{c}$ are nonnegative in general, and $\phi_{1}, \phi_{2} \in(0,1)$. At this point, what we get is that the conditions that $\phi_{1}$ and $\phi_{2}$ should satisfy are $1>\phi_{2}>c_{r} / c$ and $1>\phi_{1}>$ $c_{d} /\left(c-c_{r}\right)$.

\section{Supply Chain Coordination under Disruptions}

4.1. The Impact of Disruptions on Supply Chain Coordination. Before sale season for the coordinated supply chain, the supply chain members would make the optimal order quantity $Q^{*}$ and the optimal retail price $p^{*}$ according to revenuesharing contract as well as arranging corresponding production and operation activities. However, the disruptions would probably induce unexpected changes of the market demand in which the original optimal decisions $Q^{*}$ and $p^{*}$ may be not the optimal decisions under disruptions. It is assumed that the demand distribution function and the probability density function are, respectively, $G(x \mid p)$ and $g(x \mid p)$ under disruptions; then, the profit function of supply chain can be described as

$$
\begin{aligned}
\widetilde{\prod_{t}(Q, p)=} & p S_{g}(Q, p)+v I_{g}(Q, p)-c Q-\left(\alpha_{d}+\alpha_{m}\right) \\
& \times\left(Q-Q^{*}\right)^{+}-\left(\beta_{r}+\beta_{d}+\beta_{m}\right)\left(Q^{*}-Q\right)^{+} \\
= & (p-v) S_{g}(Q, p)-(c-v) Q-\alpha\left(Q-Q^{*}\right)^{+} \\
& -\beta\left(Q^{*}-Q\right)^{+} .
\end{aligned}
$$
$0\}$.

Here, $S_{g}(Q, p)=Q-\int_{0}^{Q} G(x \mid p) d x$ and $(a, 0)^{+}=\max \{a$,

If we use the original revenue-sharing contract to coordinate supply chain under disruptions, namely, the contract parameters satisfying (5), the profit function of supply chain members can be described as

$$
\begin{aligned}
& \widetilde{\prod_{r}^{c}}(Q, p)=\phi_{2}\left[p S_{g}(Q, p)+v I_{g}(Q, p)\right]-c_{r} Q \\
& -w_{d}^{c} Q-\beta_{r}\left(Q^{*}-Q\right)^{+} \\
& =\phi_{2}\left[\prod_{t}(Q, p)+\alpha\left(Q-Q^{*}\right)^{+}+\beta\left(Q^{*}-Q\right)^{+}\right] \\
& -\beta_{r}\left(Q^{*}-Q\right)^{+} \text {, } \\
& \prod_{d}^{c}(Q) \\
& =\phi_{1}\left[\left(1-\phi_{2}\right)\left(p S_{g}(Q, p)+v I_{g}(Q, p)\right)+w_{d}^{c} Q\right] \\
& -c_{d} Q-w_{m}^{c} Q-\alpha_{d}\left(Q-Q^{*}\right)^{+}-\beta_{d}\left(Q^{*}-Q\right)^{+} \\
& =\phi_{1}\left(1-\phi_{2}\right)\left[\prod_{t}(Q, p)+\alpha\left(Q-Q^{*}\right)^{+}+\beta\left(Q^{*}-Q\right)^{+}\right] \\
& -\alpha_{d}\left(Q-Q^{*}\right)^{+}-\beta_{d}\left(Q^{*}-Q\right)^{+}, \\
& \widetilde{c}(Q) \\
& \begin{aligned}
= & \left(1-\phi_{1}\right)\left[\left(1-\phi_{2}\right)\left(p S_{g}(Q, p)+v I_{g}(Q, p)\right)+w_{d}^{c} Q\right] \\
& +w_{m}^{c} Q-c_{m} Q-\alpha_{m}\left(Q-Q^{*}\right)^{+}-\beta_{m}\left(Q^{*}-Q\right)^{+} \\
= & \left(1-\phi_{1}\right)\left(1-\phi_{2}\right) \\
& \times\left[\widetilde{\prod}(Q, p)+\alpha\left(Q-Q^{*}\right)^{+}+\beta\left(Q^{*}-Q\right)^{+}\right] \\
& -\alpha_{m}\left(Q-Q^{*}\right)^{+}-\beta_{m}\left(Q^{*}-Q\right)^{+} .
\end{aligned}
\end{aligned}
$$

According to (9), it is shown that the profit functions of the supply chain members no longer have a linear relationship with the profit function of supply chain system. Specifically the profit functions of the supply chain members are no longer affine functions of the supply chain system's profit function. Therefore, the original revenue-sharing contract cannot coordinate the three-level supply chain under disruptions. We need to improve the revenue-sharing contract to let it have antidisruption ability.

\subsection{The Improved Revenue-Sharing Contract}

4.2.1. The Revenue-Sharing Contract Based on Quantity Discount Policy. Equation (9) shows that the disruptions have 
affected the coordination of supply chain which is no longer coordinated. Theorem 2 gives a method to recover the uncoordinated supply chain by revenue-sharing contract based on quantity discount policy.

Theorem 2. Assuming the contract parameters satisfy (10), the improved revenue-sharing contract based on quantity discount policy can coordinate the three-level supply chain:

$$
\begin{gathered}
w_{d}^{c}=\phi_{2} c-c_{r}+\psi \frac{\phi_{2}}{Q}, \\
w_{m}^{c}=\phi_{1} c-\phi_{1} c_{r}-c_{d}+\psi \frac{\phi_{1}\left(1-\phi_{2}\right)}{Q}, \\
1>\phi_{2}>\frac{c_{r}}{c+\psi / Q}, \\
1>\phi_{1}>\frac{c_{d}}{c-c_{r}+\psi\left(1-\phi_{2}\right) / Q} .
\end{gathered}
$$

Here, $\psi=\alpha\left(Q-Q^{*}\right)^{+}+\beta\left(Q^{*}-Q\right)^{+}$.

Proof. $\widetilde{\Pi}_{t}(Q, p)$ denotes the profit function of supply chain under disruptions, and taking (10) into (8), then we can get

$$
\begin{aligned}
& \widetilde{\prod_{r}^{c}}(Q, p)=\phi_{2} \prod_{t}(Q, p), \\
& \widetilde{\prod_{d}^{c}}(Q)=\phi_{1}\left(1-\phi_{2}\right) \widetilde{\prod_{t}}(Q, p), \\
& \widetilde{\prod_{m}^{c}}(Q)=\left(1-\phi_{1}\right)\left(1-\phi_{2}\right) \widetilde{\prod_{t}}(Q, p) .
\end{aligned}
$$

$1>\phi_{2}>c_{r} /(c+\psi / Q)$ and $1>\phi_{1}>c_{d} /\left(c-c_{r}+\psi\left(1-\phi_{2}\right) / Q\right)$ guarantee that $w_{d}^{c}$ and $w_{m}^{c}$ satisfy nonnegative constraint.

Equation (11) displays that the profit functions of the supply chain members are all affine functions of the whole supply chain's profit function. Hence, in this condition, the improved revenue-sharing contract can coordinate the threelevel supply chain.

It needs to be pointed out that (11) is similar to (6). The purpose is to compare the profit functions of supply chain members under disruptions with that under normal environment. In fact, $w_{d}^{c}$ and $w_{m}^{c}$ may have a variety of other forms based on quantity discount policy.

4.2.2. The Pure Form of Revenue-Sharing Contract. In Section 4.2.1, the improved revenue-sharing contract is a mixed contract based on quantity discount policy. As we point out in Section 1, perhaps the mixed contract cannot be applied to the business administration due to its high complexity and regulatory cost. As a result, in this section, we propose a pure form of revenue-sharing contract to coordinate the threelevel supply chain under disruptions.
Theorem 3. Assuming the contract parameters satisfy (12), the improved pure revenue-sharing contract can coordinate the three-level supply chain:

$$
\begin{gathered}
w_{d}^{c}=\phi_{2}\left(c+k_{1} \alpha+k_{2} \beta\right)-c_{r}-k_{2} \beta_{r}, \\
w_{m}^{c}=\phi_{1}\left(c+k_{1} \alpha+k_{2} \beta\right)-\phi_{1} c_{r}-c_{d}-k_{1} \alpha_{d} \\
-k_{2}\left(\phi_{1} \beta_{r}+\beta_{d}\right), \\
1>\phi_{2}>\frac{c_{r}+k_{2} \beta_{r}}{c+k_{1} \alpha+k_{2} \beta}, \\
1>\phi_{1}>\frac{c_{d}+k_{1} \alpha_{d}+k_{2} \beta_{d}}{c+k_{1} \alpha+k_{2} \beta-c_{r}-k_{2} \beta_{r}} .
\end{gathered}
$$

Here, $k_{1}=\left(Q-Q^{*}\right)^{+} /\left(\left(Q-Q^{*}\right)^{+}+\left(Q^{*}-Q\right)^{+}\right)$and $k_{2}=$ $-\left(Q^{*}-Q\right)^{+} /\left(\left(Q-Q^{*}\right)^{+}+\left(Q^{*}-Q\right)^{+}\right)$.

Proof. $1>\phi_{2}>\left(c_{r}+k_{2} \beta_{r}\right) /\left(c+k_{1} \alpha+k_{2} \beta\right)$ and $1>\phi_{1}>$ $\left(c_{d}+k_{1} \alpha_{d}+k_{2} \beta_{d}\right) /\left(c+k_{1} \alpha+k_{2} \beta-c_{r}-k_{2} \beta_{r}\right)$ guarantee that $w_{d}^{c}$ and $w_{m}^{c}$ satisfy nonnegative constraint.

(1) If market demand rises under disruptions, then $(Q-$ $\left.Q^{*}\right)^{+}=Q-Q^{*},\left(Q^{*}-Q\right)^{+}=0, k_{1}=1$, and $k_{2}=0$. Hence, $w_{d}^{c}=\phi_{2}(c+\alpha)-c_{r}$ and $w_{m}^{c}=\phi_{1}(c+\alpha)-\phi_{1} c_{r}-$ $c_{d}-\alpha_{d}$. Taking $w_{d}^{c}$ and $w_{m}^{c}$ into the profit functions of supply chain members, we can get

$$
\begin{aligned}
\widetilde{\prod_{r}^{c}}(Q, p) & =\phi_{2}\left[p S_{g}(Q, p)+v I_{g}(Q, p)\right]-c_{r} Q-w_{d}^{c} Q \\
& =\phi_{2}\left[\widetilde{\prod_{t}}(Q, p)-\alpha Q^{*}\right],
\end{aligned}
$$

$$
\begin{aligned}
\prod_{d}^{\widetilde{c}}(Q)= & \phi_{1}\left[\left(1-\phi_{2}\right)\left(p S_{g}(Q)+v I_{g}(Q)\right)+w_{d}^{c} Q\right] \\
& -c_{d} Q-w_{m}^{c} Q-\alpha_{d}\left(Q-Q^{*}\right)^{+} \\
= & \phi_{1}\left(1-\phi_{2}\right)\left[\widetilde{\prod}(Q, p)-\alpha Q^{*}\right]+\alpha_{d} Q^{*}
\end{aligned}
$$

$$
\begin{aligned}
\prod_{m}^{\widetilde{c}}(Q) \\
=\left(1-\phi_{1}\right)\left[\left(1-\phi_{2}\right)\left(p S_{g}(Q, p)+v I_{g}(Q, p)\right)+w_{d}^{c} Q\right] \\
\quad+w_{m}^{c} Q-c_{m} Q-\alpha_{m}\left(Q-Q^{*}\right)^{+} \\
=\left(1-\phi_{1}\right)\left(1-\phi_{2}\right)\left[\widetilde{\prod}(Q, p)-\alpha Q^{*}\right]+\alpha_{m} Q^{*}
\end{aligned}
$$

(2) If market demand falls under disruptions, then $(Q-$ $\left.Q^{*}\right)^{+}=0,\left(Q^{*}-Q\right)^{+}=Q^{*}-Q, k_{1}=0$, and $k_{2}=-1$. 
Hence, $w_{d}^{c}=\phi_{2}(c-\beta)-c_{r}+\beta_{r}$ and $w_{m}^{c}=\phi_{1}(c-\beta)-$ $\phi_{1} c_{r}-c_{d}+\phi_{1} \beta_{r}+\beta_{d}$. Taking $w_{d}^{c}$ and $w_{m}^{c}$ into the profit functions of supply chain members, we can get

$$
\begin{aligned}
& \widetilde{\prod_{r}^{c}}(Q, p)=\phi_{2}\left[p S_{g}(Q, p)+v I_{g}(Q, p)\right]-c_{r} Q-w_{d}^{c} Q \\
& -\beta_{r}\left(Q^{*}-Q\right)^{+} \\
& =\phi_{2}\left[\prod_{t}(Q, p)+\beta Q^{*}\right]-\beta_{r} Q^{*} \\
& \widetilde{\prod_{d}^{c}}(Q)=\phi_{1}\left[\left(1-\phi_{2}\right)\left(p S_{g}(Q, p)+v I_{g}(Q, p)\right)+w_{d}^{c} Q\right] \\
& -c_{d} Q-w_{m}^{c} Q-\beta_{d}\left(Q^{*}-Q\right)^{+} \\
& =\phi_{1}\left(1-\phi_{2}\right)\left[\widetilde{\prod_{t}}(Q, p)+\beta Q^{*}\right]-\beta_{d} Q^{*} \text {, } \\
& \begin{aligned}
\widetilde{\prod_{m}^{c}}(Q) & \\
= & \left(1-\phi_{1}\right)\left[\left(1-\phi_{2}\right)\left(p S_{g}(Q, p)+v I_{g}(Q, p)\right)+w_{d}^{c} Q\right] \\
& +w_{m}^{c} Q-c_{m} Q-\beta_{m}\left(Q^{*}-Q\right)^{+} \\
= & \left(1-\phi_{1}\right)\left(1-\phi_{2}\right)\left[\widetilde{\prod_{t}}(Q, p)+\beta Q^{*}\right]-\beta_{m} Q^{*}
\end{aligned}
\end{aligned}
$$

According to (13) and (14), it is demonstrated that the profit functions of the supply chain members are all affine functions of the whole supply chain's profit function, whether the market demand rises or falls under disruptions. As a result, if the contract parameters satisfy (12), the improved pure revenue-sharing contract can coordinate the three-level supply chain.

In Section 4, we put forward two forms of revenuesharing contract under disruptions with price dependent demand. One is based on quantity discount policy, and the other is a pure form. Both of the two improved revenuesharing contracts can coordinate three-level supply chain under disruptions with price dependent demand, which means they both have antidisruption ability.

\section{Model Optimization under Disruptions}

In this section, we discuss how to decide the optimal order quantity $Q^{*}$ and the optimal retail price $p^{*}$ under disruptions. Usually, we use two forms to describe how the retail price affects demand: additive form $X(p, \xi)=y(p)+\xi$ and multiplicative form $X(p, \xi)=y(p) \cdot \xi$. Here, $\xi$ is a random variable which is independent of $p$ and $0<A \leq \xi \leq B$. The probability density function and the distribution function of $\xi$ are, respectively, $f(\xi)$ and $F(\xi)$. In the range $[\underline{p}, \bar{p}], y(p)$ is continuous and nonnegative and has a second derivative. Here, $p$ and $\bar{p}$ are the minimum price and the maximum price allowed. Because $y(p)$ is the decreasing function of $p$, $d y(p) / d p<0$.

Theorem 4. For a given retail price $p$ under disruptions, if the demand is in the additive form $X(p, \xi)=y(p)+\xi$, the optimal order quantity $\bar{Q}_{t}$ can be decided by (15), while if the demand is in the multiplicative form $X(p, \xi)=y(p) \cdot \xi$, the optimal order quantity $\bar{Q}_{t}$ can be decided by (16):

$$
\begin{aligned}
& \bar{Q}_{t}=Q(p)=y(p)+G^{-1}(r), \\
& \text { here } r= \begin{cases}\frac{p-c-\alpha}{p-v} & \text { Demand rises } \\
\frac{p-c}{p-v} & \text { Demand keeps unchanged } \\
\frac{p-c+\beta}{p-v} & \text { Demand falls, }\end{cases} \\
& \bar{Q}_{t}=Q(p)=y(p) \cdot G^{-1}(r), \\
& \text { here } r= \begin{cases}\frac{p-c-\alpha}{p-v} & \text { Demand rises } \\
\frac{p-c}{p-v} & \text { Demand keeps unchanged } \\
\frac{p-c+\beta}{p-v} & \text { Demand falls. }\end{cases}
\end{aligned}
$$

Proof. Here, we only demonstrate the steps of proof when demand rises under disruptions. The steps of proof are analogous when the demand falls or keeps unchanged under disruptions. Supposing the demand rises under disruptions, the profit function of supply chain can be described as

$$
\widetilde{\prod_{t}}(Q, p)=(p-v) S_{g}(Q, p)-(c-v) Q-\alpha\left(Q-Q^{*}\right) \text {. }
$$

(1) Assume the demand is in the additive form $X(p, \xi)=$ $y(p)+\xi$. The distribution function of demand $X(p, \xi)$ can be described as $G(x \mid p)=G(x-y(p))$. Here, $S_{g}(Q, p)=Q-\int_{0}^{Q} G(x \mid p) d x=Q-\int_{A}^{Q-y(p)} G(t) d t$.

Then, (17) can be rewritten as

$$
\begin{aligned}
\widetilde{\prod_{t}(Q, p)} & =(p-v) S_{g}(Q, p)-(c-v) Q-\alpha\left(Q-Q^{*}\right) \\
& =(p-c-\alpha) Q-(p-v) \int_{A}^{Q-y(p)} G(t) d t+\alpha Q^{*} .
\end{aligned}
$$

From (18), we can get

$$
\begin{aligned}
\frac{\partial \widetilde{\prod}_{t}(Q, p)}{\partial Q} & =(p-c-\alpha)-(p-v) G(Q-y(p)), \\
\frac{\partial^{2} \widetilde{\prod}_{t}(Q, p)}{\partial Q^{2}} & =-(p-v) g(Q-y(p))<0 .
\end{aligned}
$$


Namely, for a given retail price $p$ under disruptions, $\widetilde{\Pi}_{t}(Q, p)$ is the concave function of $Q$. Hence, the optimal $\bar{Q}_{t}$ should satisfy $\partial \widetilde{\prod}_{t}(Q, p) / \partial Q=0$. Then, we can get

$$
\bar{Q}_{t}=y(p)+G^{-1}\left(\frac{p-c-\alpha}{p-v}\right) .
$$

(2) Assume the demand is in the multiplicative form $X(p, \xi)=y(p) \cdot \xi$. The distribution function of demand $X(p, \xi)$ can be described as $G(x \mid p)=G(x \mid$ $y(p))$. Here, $S_{g}(Q, p)=Q-\int_{0}^{Q} G(x \mid e) d x=Q-$ $y(p) \int_{A}^{\mathrm{Q} / y(p)} G(t) d t$.

Then, (17) can be rewritten as

$$
\begin{aligned}
\widetilde{\prod_{t}(Q, p)=} & (p-v) S_{g}(Q, p)-(c-v) Q-\alpha\left(Q-Q^{*}\right) \\
= & (p-c-\alpha) Q-(p-v) y(p) \\
& \times \int_{A}^{Q / y(p)} G(t) d t+\alpha Q^{*} .
\end{aligned}
$$

From (21), we can get

$$
\begin{aligned}
\frac{\partial \widetilde{\prod}_{t}(Q, p)}{\partial Q} & =(p-c-\alpha)-(p-v) G\left(\frac{Q}{y(p)}\right), \\
\frac{\partial^{2} \widetilde{\prod}_{t}(Q, p)}{\partial Q^{2}} & =-(p-v) g\left(\frac{Q}{y(p)}\right)<0 .
\end{aligned}
$$

Namely, for a given retail price $p$ under disruptions, $\widetilde{\Pi}_{t}(Q, p)$ is the concave function of $Q$. As a result, the optimal $\bar{Q}_{t}$ should satisfy $\partial \widetilde{\prod}_{t}(Q, p) / \partial Q=0$. Then, we can get

$$
\bar{Q}_{t}=y(p) \cdot G^{-1}\left(\frac{p-c-\alpha}{p-v}\right) .
$$

Theorem 5. If (1) $y(p)$ has IPE, (2) $\xi$ has IFGR, and (3) the demand is in the multiplicative form or additive form, then $\widetilde{\prod}_{t}(Q(p), p)$ is quasiconcave in $p$ in the range $p \in[p, \bar{p}]$.

The proof of Theorem 5 is similar to the proof in [29], which is an important reason why we omit the proof in this paper.

Theorem 6. For a given order quantity $Q$ under disruptions, if the demand is in the additive form $X(p, \xi)=y(p)+\xi$, the optimal retail price $p$ should satisfy (24), while if the demand is in the multiplicative form $X(p, \xi)=y(p) \cdot \xi$, the optimal retail price $p$ should satisfy (25):

$$
\begin{aligned}
& (p-c-\alpha) y^{\prime}(p)+y(p)+\int_{A}^{G^{-1}((p-c-\alpha) /(p-v))} u g(u) d u \\
& \quad+\frac{c-v+\alpha}{p-v} G^{-1}\left(\frac{p-c-\alpha}{p-v}\right) \\
& =0 \text { Demand rises, }
\end{aligned}
$$

$$
\begin{aligned}
& (p-c) y^{\prime}(p)+y(p)+\int_{A}^{G^{-1}((p-c) /(p-v))} u g(u) d u \\
& +\frac{c-v}{p-v} G^{-1}\left(\frac{p-c}{p-v}\right)=0 \quad \text { Demand keeps unchanged, } \\
& (p-c+\beta) y^{\prime}(p)+y(p)+\int_{A}^{G^{-1}((p-c+\beta) /(p-v))} u g(u) d u \\
& \quad+\frac{c-v-\beta}{p-v} G^{-1}\left(\frac{p-c+\beta}{p-v}\right)=0 \quad \text { Demand falls, } \\
& \left((p-v) y^{\prime}(p)+y(p)\right) \int_{A}^{G^{-1}((p-c-\alpha) /(p-v))} u g(u) d u \\
& \quad+y(p) \frac{c-v+\alpha}{p-v} G^{-1}\left(\frac{p-c-\alpha}{p-v}\right)=0 \quad \text { Demand rises, }
\end{aligned}
$$

$$
\begin{aligned}
& \left((p-v) y^{\prime}(p)+y(p)\right) \int_{A}^{G^{-1}((p-c) /(p-v))} u g(u) d u+y(p) \\
& \times \frac{c-v}{p-v} G^{-1}\left(\frac{p-c}{p-v}\right)=0 \quad \text { Demand keeps unchanged, } \\
& \left((p-v) y^{\prime}(p)+y(p)\right) \int_{A}^{G^{-1}((p-c+\beta) /(p-v))} u g(u) d u \\
& \quad+y(p) \frac{c-v-\beta}{p-v} G^{-1}\left(\frac{p-c+\beta}{p-v}\right)=0 \quad \text { Demand falls. }
\end{aligned}
$$

Proof. Here, we only demonstrate the steps of proof when demand rises under disruptions. The steps of proof are analogous when the demand falls or keeps unchanged under disruptions.

(1) Assume the demand is in the additive form $X(p, \xi)=$ $y(p)+\xi$ under disruptions. According to Theorem 4 , we get $Q(p)=y(p)+G^{-1}((p-c-\alpha) /(p-v))$. Then, the $\widetilde{\prod}_{t}(Q, p)$ can be described as

$$
\begin{aligned}
\widetilde{\prod_{t}}(Q, p)= & (p-c-\alpha) Q-(p-v) \int_{A}^{Q-y(p)} G(t) d t+\alpha Q^{*} \\
= & (p-c-\alpha) y(p)+(p-v) \\
& \times \int_{A}^{G^{-1}((p-c-\alpha) /(p-v))} u g(u) d u+\alpha Q^{*} .
\end{aligned}
$$


According to Theorem $5, \widetilde{\prod}_{t}(Q(p), p)$ is quasiconcave in $p$; namely, $\partial \widetilde{\prod}_{t}\left(Q, p^{*}\right) / \partial p=0$ has a unique solution. That is, $(p-c-\alpha) y^{\prime}(p)+y(p)+\int_{A}^{G^{-1}((p-c-\alpha) /(p-v))} u g(u) d u+((c-v+$ $\alpha) /(p-v)) G^{-1}((p-c-\alpha) /(p-v))=0$ has a unique optimal solution $p$.

(2) Assume the demand is in the multiplicative form $X(p, \xi)=y(p) \cdot \xi$ under disruptions. According to Theorem 4 , we get $Q(p)=y(p) \cdot G^{-1}((p-c-\alpha) /(p-$ $v))$. Then, the $\widetilde{\prod}_{t}(Q, p)$ can be described as

$$
\begin{aligned}
\widetilde{\prod_{t}}(Q, p)= & (p-c-\alpha) Q-(p-v) y(p) \\
& \times \int_{A}^{Q / y(p)} G(t) d t+\alpha Q^{*} \\
= & (p-c-\alpha) y(p) \cdot G^{-1}\left(\frac{p-c-\alpha}{p-v}\right) \\
& -(p-v) y(p) \int_{A}^{G^{-1}((p-c-\alpha) /(p-v))} G(t) d t \\
& +\alpha Q^{*} \\
= & (p-v) y(p) \int_{A}^{G^{-1}((p-c-\alpha) /(p-v))} u g(u) d u \\
& +\alpha Q^{*} .
\end{aligned}
$$

Similarly, according to Theorem $5, \widetilde{\prod}_{t}(Q(p), p)$ is quasiconcave in $p$; namely, $\partial \widetilde{\prod}_{t}\left(Q, p^{*}\right) / \partial p=0$ has a unique solution. That is, $\left((p-v) y^{\prime}(p)+y(p)\right) \int_{A}^{G^{-1}((p-c-\alpha) /(p-v))} u g(u) d u$ $+y(p)((c-v+\alpha) /(p-v)) G^{-1}((p-c-\alpha) /(p-v))=0$ has a unique optimal solution $p$.

It is obvious that the optimal retail price would be changed under disruptions according to Theorem 6 . Thus, the retailer would adjust his retail price to maximize his profit. However, the price adjustment could incur new costs. If only the retailer bears the new cost, the improved revenuesharing contract designed in Section 4 would not coordinate the three-level supply chain. Thus, to make the supply chain respond to disruptions and keep coordination, it is necessary to make the retailer, the distributor, and the manufacturer share the cost proportionately. In other words, if only the retailer bears the cost, the distributor and the manufacturer should offer subsidies. Theorem 7 proposes the following revenue-sharing contract.

Theorem 7. The retailer will adjust the retail price to meet market demand under disruptions. Assume only the retailer bears the price adjustment cost $\Gamma$. The following revenuesharing contract can coordinate three-level supply chain with price dependent demand and can be used to deal with disruptions. (1) The distributor provides the revenue-sharing contract $\left(w_{d}^{c}, \phi_{2}\right)$ to the retailer and the manufacturer provides the revenue-sharing contract $\left(w_{m}^{c}, \phi_{1}\right)$ to the distributor where the contract parameters should satisfy (28); (2) the subsidies that the distributor should provide for the retailer are $\left(1-\phi_{2}\right) \Gamma$, and the subsides that the manufacturer should provide for the distributor are $\left(1-\phi_{1}\right)\left(1-\phi_{2}\right) \Gamma$ :

$$
\begin{gathered}
w_{d}^{c}=\phi_{2} c-c_{r}+\psi \frac{\phi_{2}}{Q}, \\
w_{m}^{c}=\phi_{1} c-\phi_{1} c_{r}-c_{d}+\psi \frac{\phi_{1}\left(1-\phi_{2}\right)}{Q}, \\
1>\phi_{2}>\frac{c_{r}}{c+\psi / Q}, \\
1>\phi_{1}>\frac{c_{d}}{c-c_{r}+\psi\left(1-\phi_{2}\right) / Q} .
\end{gathered}
$$

Here, $\psi=\alpha\left(Q-Q^{*}\right)^{+}+\beta\left(Q^{*}-Q\right)^{+}$.

\section{Numerical Example}

Assume a three-level supply chain consists of one retailer, one distributor, and one manufacturer and revenue-sharing contract is used to coordinate the supply chain. The contract parameters are as follows: $v=3, c_{r}=1, c_{d}=2, c_{m}=5, w_{d}^{d}=$ 15 , and $w_{m}^{d}=18$.

Assume the demand is in the additive form before disruptions. The calculation can refer to the following if the demand is in the multiplicative form. Here, $y(p)=450-10 p$ and $\xi$ has a uniform distribution in the range $[50,100]$. Then, $f(\xi)=1 / 50, F(\xi)=(\xi-50) / 50$, and $F^{-1}(\xi)=50+50 \xi$. The demand is also in the additive form under disruptions, but $y(p)=300-10 p$ and $\xi$ has a uniform distribution in the range $[30,70]$. Then, $g(\xi)=1 / 40, G(\xi)=(\xi-30) / 40$, and $G^{-1}(\xi)=$ $30+40 \xi$. To simplify the analysis, assume $\alpha_{d}=\alpha_{m}=\beta_{r}=$ $\beta_{d}=\beta_{m}=1$.

(1) For the centralized supply chain system before disruption, we get

$$
\begin{aligned}
\widetilde{\prod_{t}}(Q, p)= & (p-c) Q-(p-v) \int_{A}^{Q-y(p)} F(t) d t \\
= & (p-c) y(p)+(p-v) \\
& \times \int_{A}^{F^{-1}((p-c) /(p-v))} u f(u) d u \\
= & (p-8)\left(500-10 p+25 \frac{p-8}{p-3}\right) .
\end{aligned}
$$

Figure 1 shows that $\prod_{t}(Q, p)$ is quasiconcave in $p$. Then, we calculate the optimal retail price $p^{*}=30.21$, the optimal order quantity $Q^{*}=239$, and the profit of supply chain $\prod_{t}\left(Q^{*}, p^{*}\right)=4848.6$. 
TABLE 1: The parameters of three-level supply chain with price dependent demand.

\begin{tabular}{|c|c|c|c|c|}
\hline & $\begin{array}{l}\text { The demand } \\
\text { satisfying } F(x \mid p)\end{array}$ & \multicolumn{3}{|c|}{ The demand satisfying $G(x \mid p)$ under disruptions } \\
\hline & $\begin{array}{l}\text { With the } \\
\text { traditional } \\
\text { revenue-sharing } \\
\text { contract }\end{array}$ & $\begin{array}{l}\text { With the original } \\
\text { revenue-sharing } \\
\text { contract }\end{array}$ & $\begin{array}{l}\text { With the } \\
\text { revenue-sharing } \\
\text { contract based on } \\
\text { quantity discount policy }\end{array}$ & $\begin{array}{c}\text { With the pure form } \\
\text { of revenue-sharing } \\
\text { contract }\end{array}$ \\
\hline $\begin{array}{l}\text { The order quantity } \\
Q\end{array}$ & 239 & 152 & 165 & 165 \\
\hline $\begin{array}{l}\text { The expectation } \\
\text { sale quantity } \\
S(Q, p)\end{array}$ & 222 & 136 & 149 & 149 \\
\hline The retail price $p$ & 30.21 & 20.95 & 19.98 & 19.98 \\
\hline $\begin{array}{l}\text { The profit of supply } \\
\text { chain } \prod\end{array}$ & 4848.6 & 1459.2 & 1483 & 1483 \\
\hline
\end{tabular}

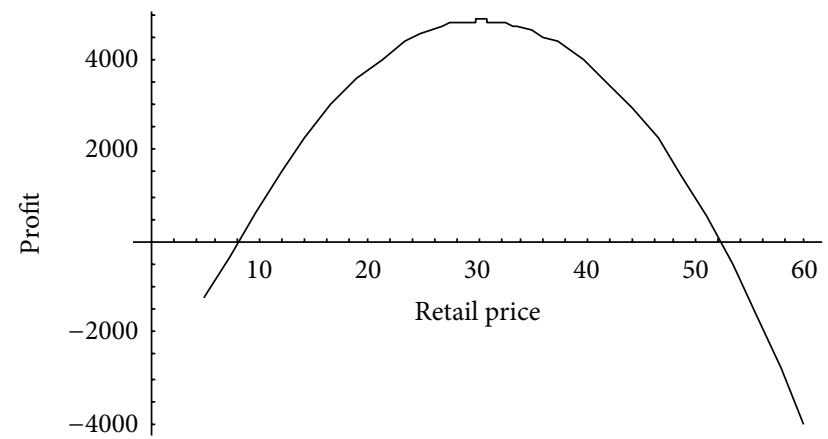

FIGURE 1: The relationship between the profit of supply chain and the retail price before disruptions.

(2) For the centralized supply chain under disruptions, we get

$$
\begin{aligned}
\widetilde{\prod_{t}(Q, p)=} & (p-c) Q-(p-v) \int_{A}^{Q-y(p)} G(t) d t \\
& -\alpha\left(Q-Q^{*}\right)^{+}-\beta\left(Q^{*}-Q\right)^{+} \\
= & (p-c+\beta) y(p) \\
& +(p-v) \int_{A}^{G^{-1}((p-c+\beta) /(p-v))} u g(u) d u-\beta Q^{*} \\
= & (p-5)\left(330-10 p+20 \frac{p-5}{p-3}\right)-717 .
\end{aligned}
$$

Figure 2 indicates that $\widetilde{\prod}_{t}(Q, p)$ is quasiconcave in $p$. Similarly, we figure out the optimal retail price $\bar{p}^{*}=19.98$, the optimal order quantity $\bar{Q}^{*}=165$, and the profit of supply chain $\prod_{t}\left(Q^{*}, p^{*}\right)=1483$.

From the discussion above, we can see that the demand falls due to the disruptions and the profit of supply chain

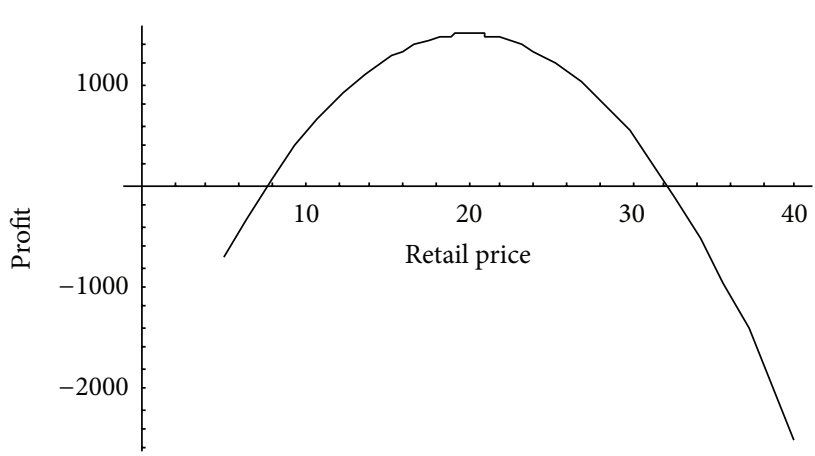

FIGURE 2: The relationship between the profit of supply chain and the retail price under disruptions.

declines dramatically under disruptions. Therefore, it is essential to use revenue-sharing contract to coordinate the three-level supply chain.

According to the formula in this paper, we can calculate the order quantity, the expectation sale quantity, the retail price, and the profit of supply chain in different conditions, which are shown in Table 1 where $\phi_{1}=0.5, \phi_{2}=0.45$.

From Table 1, we observe that the disruptions have significantly influenced the supply chain operation. The improved revenue-sharing contract discussed in this paper, aiming at coordinating the three-level supply chain under disruptions, is an effective way to encourage the supply chain members to actively participate in the operations of supply chain. In addition, it could contribute to fulfilling the potential of the supply chain, increasing the order quantity, and maximizing the profits of the supply chain.

It is known that the profits of the supply chain members would be affected to different degrees by the contract parameters. Therefore, the improved revenue-sharing contract could give guarantee that the profits of the supply chain members would not be less than the profit that they obtain in decentralized supply chain. That is, the contract parameters need to be limited. 


\section{Conclusions}

The disruptions will make great impacts on the coordination of the supply chain and could cause the coordinated supply chain to be no longer coordinated. The revenue-sharing contract based on the three-level supply chain is discussed in this paper in response to disruptions. The conclusions are as follows. (1) Suppose the retailer faces a stochastic demand relying on price before disruptions. The revenue-sharing contract could coordinate three-level supply chain when the parameters satisfy (5); (2) the original revenue-sharing contract cannot coordinate three-level supply chain under disruptions as the deviation costs are caused by the overtime production for an increased demand under disruptions, which are not taken into account in the original revenue-sharing contract; (3) two forms of revenue-sharing contract are put forward: one is a mixed form based on quantity discount policy and the other is a pure form. Both have antidisruptions ability; (4) the improved revenue-sharing contract is optimized by supposing that the demand is in the additive form (or in the multiplicative form) and develops the methods to decide the optimal order quantity and the optimal retail price.

It is worth noting that this essay is conducted in the risk neutral case. However, in reality, the attitude to the disruptions of the supply chain members is different; namely, the supply chain members have different decision preferences. Therefore, the next step to carry out this research is to take the decision preference into account.

\section{Conflict of Interests}

The authors declare that there is no conflict of interests regarding the publication of this paper.

\section{Acknowledgments}

This research was supported by the Ministry of Education of China: Grant-in-aid for Humanity and Social Science Research (no. 10YJC630188), the Major Program of the National Social Science Foundation of China (no. 2012\&ZD214), and the Fundamental Research Funds for the Central Universities (nos. 2012B13914 and 2013B30714).

\section{References}

[1] C. Huang, G. Yu, S. Wang, and X. Wang, "Disruption management for supply chain coordination with exponential demand function," Acta Mathematica Scientia, Series B: English Edition, vol. 26, no. 4, pp. 655-669, 2006.

[2] T. J. Xiao, X. T. Qi, and G. Yu, "Coordination of supply chain after demand disruptions when retailers compete," International Journal of Production Economics, vol. 109, no. 12, pp. 162-179, 2007.

[3] T. J. Xiao and X. T. Qi, "Price competition, cost and demand disruptions and coordination of a supply chain with one manufacturer and two competing retailers," OMEGA: The International Journal of Management Science, vol. 36, no. 5, pp. 741-753, 2008.

[4] K. Chen and T. Xiao, "Demand disruption and coordination of the supply chain with a dominant retailer," European Journal of Operational Research, vol. 197, no. 1, pp. 225-234, 2009.
[5] H. Yu, J. Chen, and G. Yu, "How to coordinate supply chain under disruptions," Systems Engineering: Theory \& Practice, vol. 25, no. 7, pp. 9-16, 2005.

[6] H. Yu, J. Chen, and G. Yu, "Managing wholesale price contract in the supply chain under disruptions," System EngineeringTheory and Practice, vol. 26, no. 8, pp. 33-41, 2006.

[7] C.-X. Teng, Y.-X. Hu, and Y.-S. Zhou, "Supply chain network equilibrium with stochastic demand under disruptions," Systems Engineering: Theory \& Practice, vol. 29, no. 3, pp. 16-20, 2009.

[8] C. Ma and Y. W. Zhou, "Supply chain coordination under disruptions by adjusting option contract," Journal of Hefei University of Technology, vol. 32, no. 3, pp. 430-434, 2009.

[9] J. L. Zhang and J. Chen, "Vender manage inventory under disruption," Chinese Journal of Management Science, vol. 16, no. 5, pp. 71-76, 2008.

[10] L. Sun and Y. H. Ma, "Supply chain coordination in emergent events using a Revenue-sharing contract," Journal of Beijing University of Chemical Technology, vol. 35, no. 3, pp. 98-100, 2008.

[11] E. B. Cao and M. Y. Lai, "Supply chain coordination under disruptions with revenue-sharing contract," Journal of Wuhan University of Science and Technology (Natural Science Edition), vol. 30, no. 5, pp. 557-560, 2007.

[12] L. N. Jiang and W. T. Cui, "Supply chain coordination under target rebate contract with demand disruption," Operations Research and Management Science, vol. 21, no. 2, pp. 8-13, 2012.

[13] Y. H. Qin and X. Y. Cao, "Option contracts under disruptions for supply chain coordination," Forecasting, vol. 31, no. 1, pp. 60-64, 2012.

[14] Y. H. Qin and X. Y. Cao, "The impact of emergencies on the closed-loop supply chain under rebate and penalty contracts," Journal of Industrial Engineering and Engineering Management, vol. 26, no. 3, pp. 96-101, 2012.

[15] W.-G. Zhang, J. Fu, H. Li, and W. Xu, "Coordination of supply chain with a revenue-sharing contract under demand disruptions when retailers compete," International Journal of Production Economics, vol. 138, no. 1, pp. 68-75, 2012.

[16] J. Hou, A. Z. Zeng, and L. Zhao, "Coordination with a backup supplier through buy-back contract under supply disruption," Transportation Research Part E: Logistics and Transportation Review, vol. 46, no. 6, pp. 881-895, 2010.

[17] X. T. Qi, J. F. Bard, and G. Yu, "Supply chain coordination with demand disruptions," OMEGA: The International Journal of Management Science, vol. 32, no. 4, pp. 301-312, 2004.

[18] H. Wang and J. S. Hu, "Coordination mechanism analysis of three-level supply chain under disruption," Journal of Qingdao University (Natural Science Edition), vol. 19, no. 3, pp. 71-76, 2006.

[19] J. S. Hu and H. Wang, "The price discount contract analysis of three-level supply chain under disruption," Chinese Journal of Management Science, vol. 15, no. 3, pp. 103-107, 2007.

[20] Q. H. Pang, "Three-level supply chain coordination under disruption with revenue-sharing contract," Chinese Journal of Management Science, vol. 18, no. 4, pp. 101-106, 2010.

[21] Z. D. Sun and Z. L. Zou, "The coordination mechanism of threelevel supply chain based on buyback contract under disruption," Journal of Qingdao University of Technology (Social Science Edition), vol. 16, no. 2, pp. 63-69, 2012.

[22] C.-H. Chiu, T.-M. Choi, and C. S. Tang, "Price, rebate, and returns supply contracts for coordinating supply chains with 
price-dependent demands," Production and Operations Management, vol. 20, no. 1, pp. 81-91, 2011.

[23] J. Chen and P. C. Bell, "Coordinating a decentralized supply chain with customer returns and price-dependent stochastic demand using a buyback policy," European Journal of Operational Research, vol. 212, no. 2, pp. 293-300, 2011.

[24] H. Y. Chen, Y. H. Chen, C.-H. Chiu, T.-M. Choi, and S. Sethi, "Coordination mechanism for the supply chain with leadtime consideration and price-dependent demand," European Journal of Operational Research, vol. 203, no. 1, pp. 70-80, 2010.

[25] Y. X. Zhao, T. M. Choi, T. C. E. Cheng et al., "Buyback contracts with price-dependent demand: effects of demand uncertainty," European Journal of Operational Research, vol. 239, no. 3, pp. 663-673, 2014.

[26] H. Yu and J. Chen, "Response to the disruption of supply chain with price-depended demand," System Engineering Theory and Practice, vol. 27, no. 3, pp. 36-41, 2007.

[27] G. P. Cachon and M. A. Lariviere, "Supply chain coordination with revenue-sharing contracts: strengths and limitations," Management Science, vol. 51, no. 1, pp. 30-44, 2005.

[28] I. Giannoccaro and P. Pontrandolfo, "Supply chain coordination by revenue sharing contracts," International Journal of Production Economics, vol. 89, no. 2, pp. 131-139, 2004.

[29] Y. Li, Y. Chen, and H. Han, "Analysis of a supply contract for coordinating the newsvendor with price dependent demand," Working Paper, Chinese University of Hong Kong, 2008. 


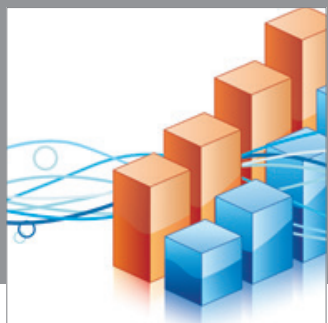

Advances in

Operations Research

mansans

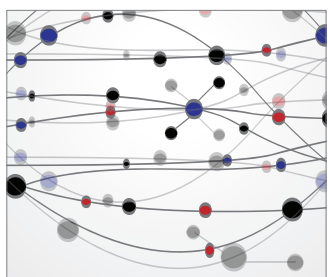

The Scientific World Journal
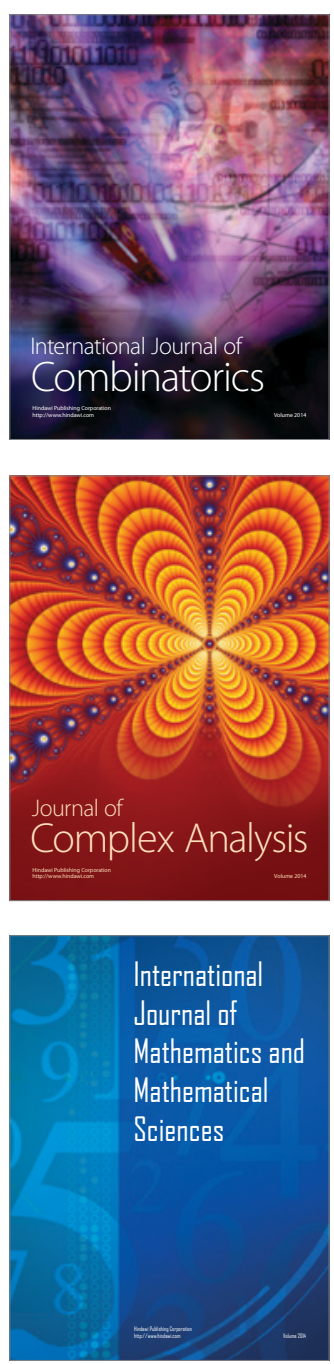
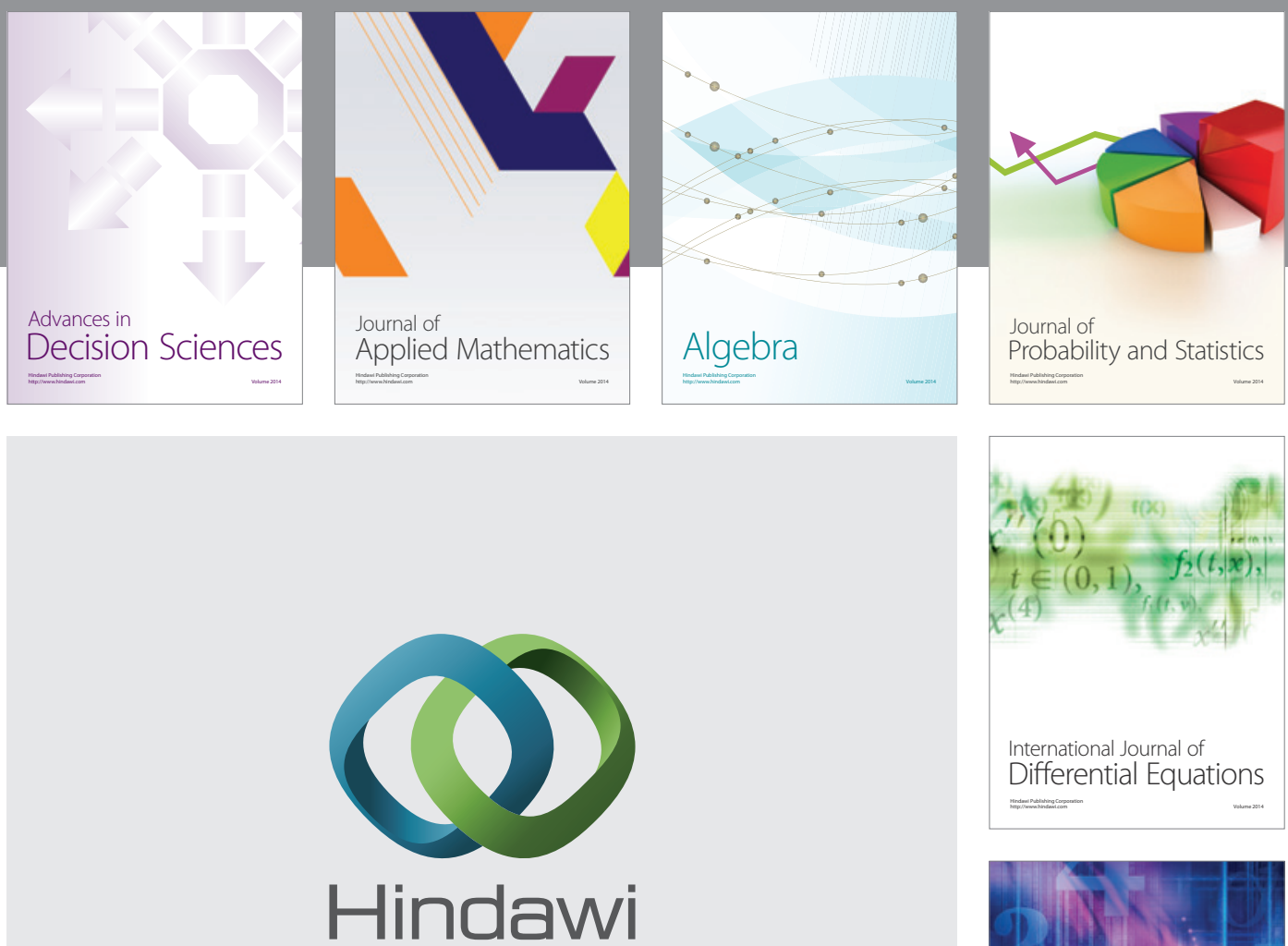

Submit your manuscripts at http://www.hindawi.com
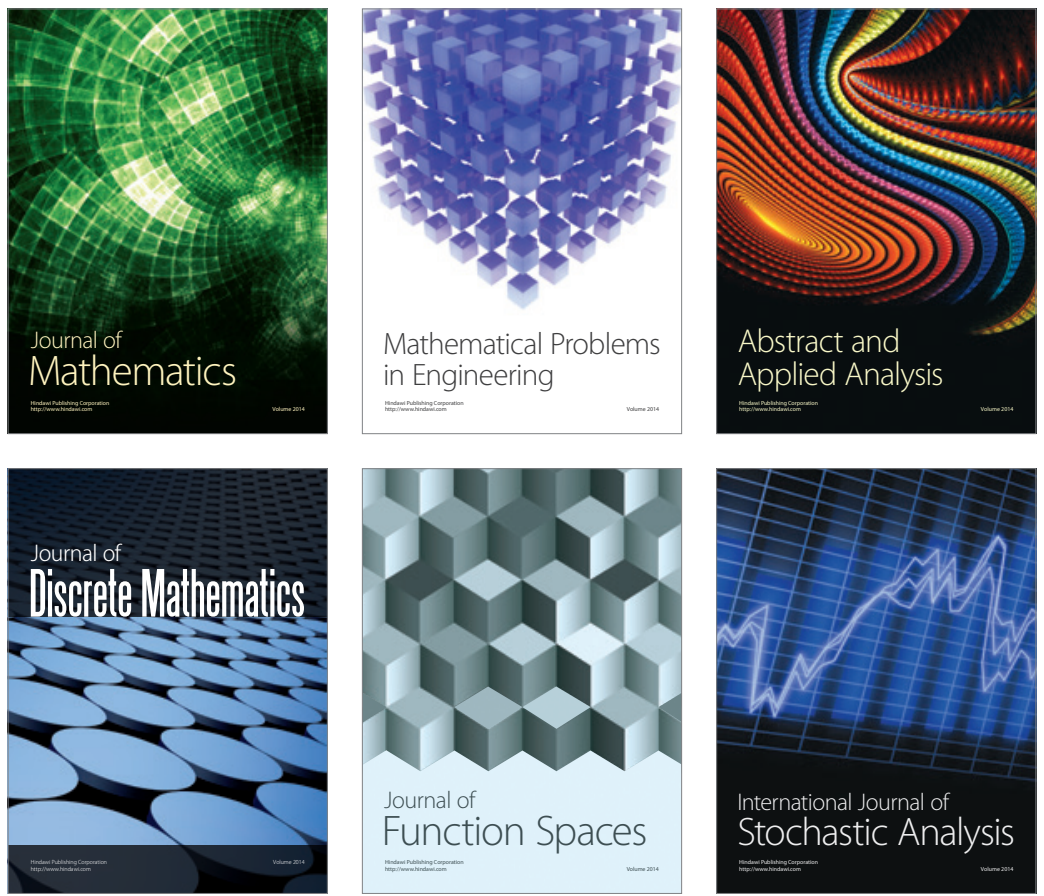

Journal of

Function Spaces

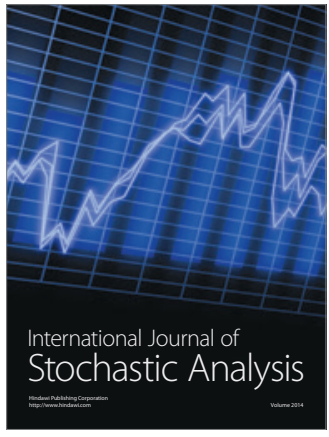

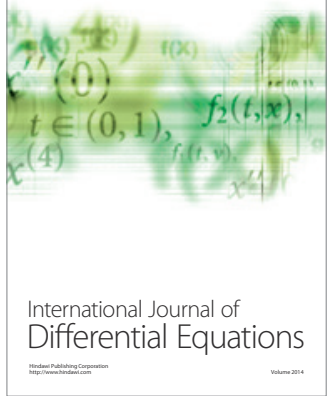
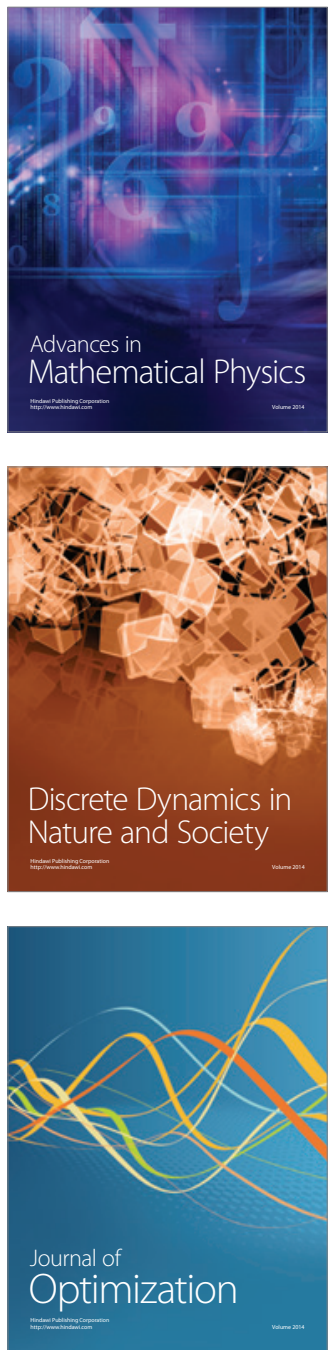